\title{
PREFACE
}

DESCRIBING the difficulties of her own art in metaphors of another, Emily Dickinson once wrote,

I found the words to every thought

I ever had-but One-

And that-defies me-

As a Hand did try to chalk the Sun

To Races-nurtured in the Dark-

How would your own-begin?

Can Blaze be shown in Cochineal-

Or Noon-in Mazarin?

Readers who have sought the words Emily Dickinson so successfully found for her poetry have not always been as fortunate. For some time it was not even possible to find the poems as she wrote them, but with the publication in 1955 of Thomas H. Johnson's definitive three-volume variorum edition, The Poems of Emily Dickinson, they became fully available. The purpose of this concordance is to make "the words to every thought" in the poems of that edition equally available. For some this purpose will best be served by the use of the concordance to locate poems or parts of poems that have been forgotten. The publishing history of her work being what it is, this service is more important than it might be for other poets; lines and stanzas that appear in the early editions of Emily Dickinson's poetry as separate works can, through this concordance, be restored to the poems from which they were originally taken. Yet such a service hardly justifies the human and inhuman labor involved in making a computer concordance. Of far greater value is the index that the concordance provides to the words, and consequently to the images and ideas, of Emily Dickinson's art. And by indexing the words that present those images and ideas along with their contexts in the line-contexts which include the poet's alternative 
choices for these words-the concordance becomes much more useful than a listing that merely locates the isolated, inert words of her vocabulary. With its inclusion of variants and with its presentation of the entries in approximate chronological order under a given index word, this concordance is potentially helpful for studies of Emily Dickinson's poetic development. The concordance could also be indispensable for biographical and canonical studies, and the preservation at Cornell University of the tape from which the concordance was made allows for further possible studies of Emily Dickinson's metrics and methods of composition.

How electronic means were invoked to attain these humanistic ends is fully explained in James A. Painter's "Programmer's Preface" to A Concordance to the Poems of W. B. Yeats (Ithaca, N.Y., 1963). There is also a brief résumé of the computer techniques specifically used for the concordance of Emily Dickinson's poetry in my "Emily Dickinson and the Machine" (Studies in Bibliography, XVIII[1965]). The effective use of this concordance depends, however, not so much on understanding the technicalities of how the concordance was made as on being aware of the particular features of its format. These are described below under appropriate subheadings. The nature of the text of Emily Dickinson's poetry on which this concordance is based and the various modifications made in that text for the concordance are explained after the description of the format. The last section of the preface discusses what is probably the most difficult task in editing Emily Dickinson's poems, the treatment of her numerous and important variants.

\section{FORMAT OF THE CONCORDANCE}

\section{Index Word}

The alphabetically arranged index words consist of all the words in Emily Dickinson's poetry except the so-called "nonsignificant" omitted words listed below. Bracketed variant words and phrases are indexed along with the words from the main texts. When the entries under an index word are continued on the next page of the concordance, the index word is repeated and CONTINUED is printed in parentheses alongside the word. In its alphabetizing, the computer was instructed to treat the apostrophe as a letter; consequently such a form as the singular possessive of a noun follows the nominative singular but precedes the nominative plural.

The few hyphenated compounds in Emily Dickinson's poetry were automatically cross-referenced by the computer, which indexed the second half of the compound and then printed alongside it a SEE followed by the first part of the compound. Unhyphenated compounds were crossreferenced by the editor in the same way only when they were so unusual 
that a user in search of all occurrences of a word could not be expected to anticipate them. Ashine, for instance, is cross-referenced from sHINE, but there is no reference from STIR to ASTIR. (Unusual compounds not hyphenated by Emily Dickinson, or groups of letters that belonged together as index "words," were also kept together to make possible such index entries as $\mathrm{A}-\mathrm{B}-\mathrm{C}$, AUTO DA FE, and I. E.) Emily Dickinson's numerous misspellings, eccentric contractions, and uncommon variant spellings were cross-referenced only when they are not either alphabetically adjacent to their familiar spellings or separated merely by different forms of the same word. Thus wo was not cross-referenced to woE, which follows it, but vaIL and veIL, separated by forty-six entries, were cross-referenced. Much of the cross-referencing in the concordance is one way only-from the expected to the unexpected. EYE is cross-referenced to E'E but not vice versa. In instances where more than one spelling occurs in the text (CONCEIve and Concieve), cross-referencing was done both ways, lest the user suppose Emily Dickinson a consistent misspeller. But again, different spellings were not cross-referenced when adjacent to each other or separated only by forms of the same word. There could be, of course, no end to crossreferencing; the reader who wants to be certain he has all the forms of a particular word should consult the appendix, which contains a complete record of the poet's indexed vocabulary, arranged according to the frequency of the words.

Certain words in Emily Dickinson's poetic vocabulary were omitted from the indexing because the cost of including them would have been disproportionate to their value for users of the concordance. To index every occurrence of "the" and "a" would have entailed the addition of 6,138 and 2,681 lines, respectively-an increase in the bulk of the concordance of approximately 10 per cent. The number of these omitted words is quite small compared to the number customarily dropped from manual concordances. The sheer labor involved in a manual concordance makes it desirable to omit as many words as possible; but in a computer concordance the main considerations are space and consistency in the omission of lowfrequency forms of high-frequency words. Examples of the kinds of words usually deleted from concordances but retained here are LIKE and As (for lists of Emily Dickinson's similes), BE (for Emily Dickinson's unusual and extensive use of the subjunctive form of this verb), and the pronouns I, WE, YOU, HE, and SHE, along with their related forms (for their relevance to biographical and "persona" studies). Because the concordance provides the context of each word, it was not felt necessary to distinguish homographs among the indexed words. Among the unindexed words seven potentially important homographs appeared: the nouns ART, MAY, MIGHT, wILL, and wont, the main verb wiLt, and the adjective wont. These were 
separated from "nonsignificant" verbs with the same spelling and then indexed. (No homographs were found among Emily Dickinson's apostropheless contractions CANT and TWILL.)

The following is a complete list, together with their frequencies, of the words in Emily Dickinson's vocabulary that were omitted from the indexing.

\begin{tabular}{|c|c|c|c|c|c|c|c|}
\hline & 2681 & 'EM & 2 & OTHER . & 143 & THOUGH & 89 \\
\hline ALTHo' & 1 & FOR & 845 & OTHERS & 23 & THRO . & 2 \\
\hline LTHOUGH & 11 & FROM & 381 & OTHER'S & 9 & THRO' & 20 \\
\hline$A M \quad \ldots$ & 79 & HAD . & 298 & HALL . & 104 & THROUGH & 77 \\
\hline . & 1 & HAD'NT & 1 & SHALT & 8 & THUS . . & \\
\hline AN $\ldots$ & 371 & HADST & 1 & SHANT . & 2 & TIS . & \\
\hline AND ... & 2349 & HAD’ST & 3 & SH'D . . & 8 & T'Is & \\
\hline ANOTHER . & 44 & HAS .. & 174 & SHOULD . & 120 & 'TIS . & 161 \\
\hline ANOTHER'S & 2 & HAS'NT & 2 & SHOULD'NT & 3 & 'TIS'NT & \\
\hline A'NT $\ldots \ldots$ & 1 & HAST . & 16 & so $\ldots$. & 637 & то . . & 2384 \\
\hline $\mathrm{ARE}$ & 334 & НАТН & 29 & so's & 1 & гоO & 36 \\
\hline ART (vb.). & 221 & HAVE. & 289 & 'T. & 1 & WAS & \\
\hline $\mathrm{AT} \ldots \ldots$ & 421 & HAV'NT & 3 & THAN & 221 & T'WAS & \\
\hline вотн . . & 25 & HERE . & 84 & THAT . & 1298 & TWAS & 13 \\
\hline$\ldots$ & 808 & HERE'S . & 3 & THAT'S & 18 & 'TWAS'NT & \\
\hline 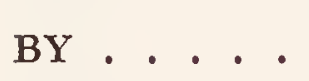 & 454 & HOW . & 308 & THE . . & 6138 & TWERE . & \\
\hline CAN & 179 & HOWEVER & 12 & THEIR . . & 215 & T'WERE & \\
\hline CANNOT . . & 117 & IF $\ldots$ & 447 & THEIRS & 1 & 'TWERE . . & 19 \\
\hline CAN'ST . . & 3 & IN & 1223 & THEIR'S & 6 & TWILL (vb.) & \\
\hline CANT (vb.) & 9 & INTO & 34 & THEM . & 138 & 'TWILL . . & 10 \\
\hline C'D . . . . & 3 & IS . & 1201 & THEMSELF & 9 & TWOULD . . & \\
\hline COULD . . & 275 & ISN'T & 1 & THEMSELVES & 20 & 'TWOULD. & 15 \\
\hline COULD'NT 。 & 6 & IS'NT & 2 & THEN $\ldots$ & 354 & 'TWOULD'NT & \\
\hline COULD'ST . & 4 & IT . & 1256 & THERE . . . & 220 & UPON $\ldots$ & \\
\hline DID . & 150 & ITS & 22 & THEREFORE & 15 & WAS . . & 06 \\
\hline DID'NT & 8 & IT'S & 312 & THERE'LL . & 1 & WAS'NT & \\
\hline DIDST & 1 & ITSELF . . . & 104 & THERE'S . & 29 & WAS'T . & \\
\hline DID'ST & 4 & MAY (vb.) & 141 & THESE . & 87 & W'D . . & \\
\hline DINNA & 2 & MIGHT (vb. & ) 64 & THEY . & 314 & WERE & 269 \\
\hline Do . . & 170 & MUST $\ldots$ & 127 & THEY'D & 5 & WERT & \\
\hline DOES . & 45 & NEITHER & 22 & THEY'LL & 5 & wh'. & \\
\hline DOES'NT . & 11 & No $\ldots$ & 395 & THEY'RE . & 9 & WHAT $\ldots$ & 278 \\
\hline ONT $\ldots$ & 24 & NOR. & 163 & THIS . . . & 430 & WHATSOE'ER & \\
\hline DON'T & 1 & NOT & 828 & THO & 3 & WHEN $\ldots$ & \\
\hline OST . & 7 & now & 131 & тно' & 27 & WHERE & 146 \\
\hline Отн & 38 & OF . & 1996 & 'тно' & 1 & WHEREVER & \\
\hline $\mathrm{ACH}$ & 74 & ON . & 391 & THOSE . . . & 89 & WHETHER . & 20 \\
\hline EITHER . . & 11 & OR. & 460 & THOSOEVER & 1 & WHICH . & 116 \\
\hline
\end{tabular}




\begin{tabular}{|c|c|c|c|c|c|c|}
\hline WHO & 223 & WHOM & 46 & wILL (vb.) & 208 & WOULD . \\
\hline WHO'D & 1 & WHOSE & 105 & wILt (aux.) & 6 & WOULDN'T \\
\hline WHOEVER & 3 & WHO'vE & 2 & WITH ... & 603 & WOULD'NT \\
\hline WHO'LL . & 2 & WHY . & 40 & WONT (vb.) & 15 & WOULD'ST \\
\hline
\end{tabular}

Several recent studies have shown that some of these omitted words could be very important in analyses of style. But for those who need them, all is not lost. It is possible for a computer to retrieve them from the compiete magnetic tape of the concordance.

\section{Text Line}

Indented below each indexed word appear the lines of poetry containing that word. Many of the lines include bracketed insertions of variant words or phrases to be found in Emily Dickinson's manuscripts. (For the provenance of these variants and the methods used to include them in the text lines of the concordance, see the discussion of the text and variants, below.) The bracketed insertions follow the words for which they are variants. When more than one variant word or phrase is listed for the reading in a particular main text of Johnson's edition, the alternative variants are separated from one another within the brackets by slash marks. Thus Emily Dickinson's famous description of despair in poem number 640 , together with the two variants written in the manuscript for the last word in the line, appears as follows in the concordance:

\section{AND THAT WHITE SUSTENANCE-[EXERCISE/PRIVILEGE]}

Here as elsewhere in the concordance the word or phrase that the variants replace can usually be determined simply by noting the number of syllables in the variant and in the words preceding the bracketed insertion.

The text lines under each index word are arranged in order, according to their poem and line numbers. A line is repeated if the index word occurs in it more than once. Widely spaced dots separate the text lines from the shortened first lines used as titles for the poems. These dots are omitted in lines longer than forty-six spaces, which are continued, indented, on the line below. Lines longer than sixty-nine spaces-all that an eighty-space IBM card could contain in addition to poem and line numbers-had to be divided and the parts preceded or followed by ellipses, indicated by three closely spaced dots, which should not be confused with the widely spaced ones that follow the text lines. Because of the shortness of Emily Dickinson's lines, even when extended with inserted variants, using part of a line instead of the whole was seldom necessary. An extreme illustration of how a line distended with bracketed 
variants had to be divided can be seen in the sixth line of number 1420 . The line with all its variants reads as follows:

\section{BEFORE THE QUICK [RIPE/PEAL/DRUM/DRUMS/BELLS/BOMB/BURST /FLAGS/STEP/TICK/SHOUTS/PINK/RED/BLADE] OF DAY}

The line had to be divided in two places in the concordance: the first section ends with an ellipsis after вомв, the second begins with an ellipsis before BURST and ends with an ellipsis after RED, and the last section begins with an ellipsis before BLADE.

\section{First Line}

Under the heading FIRST LINE are given the shortened first lines of the poems from which the text lines are taken. These first lines serve, in effect, as titles for the poems, and they contain as many complete words of the first line as could be fitted into the twenty-four spaces available for them in the format of the concordance. In a dozen or so instances, the necessary shortening of the lines resulted in nearly identical titles (number 1244, THE BUTTERFLY'S, and number 1387, THE BUTTERFLY'S NUMIDIAN, for example), yet this method of identifying the poems seemed preferable to any other. To have identified the lines of a poem only by its number, for instance, would have assumed that readers of Emily Dickinson were more familiar with her poem numbers than readers of Shakespeare's sonnets appear to be with those numbers. Furthermore, using only Johnson's numbering of the poems would have rendered the concordance almost useless for anyone working from an edition or anthology that does not adopt Johnson's poem numbers. Another possible alternative-making up titles for the 1,749 poems Emily Dickinson left untitled-was unattractive if only because this had been tried, with some horrible results, by the poet's first editors. The use of shortened first lines as identifying titles in the concordance also obviated the need for a separate list of abbreviated titles like those in the Cornell concordances of Arnold and Yeats. The twenty-six titles that Emily Dickinson did use are treated as lines of poetry and indexed accordingly; they are distinguished by a " $T$ " in the line-number column.

\section{Poem Number}

Poem numbers rather than page numbers of The Poems of Emily Dickinson are used to identify the source of the indexed lines because they have been adopted by other editors following Johnson. (If only page numbers had been employed, the concordance would be limited to use with Johnson's edition.) A more valuable result of giving the poem numbers-and one of the most significant features of the format of the con- 
cordance-is the roughly chronological order of these numbers. By arranging the lines under a particular index word according to the numbers of the poems in which they appear, the concordance presents in approximate chronological order the poet's uses of any indexed word. The following table of poem numbers and dates of composition is constructed from the approximate dates in The Poems of Emily Dickinson; with it the user of the concordance should be able to determine the approximate dates at which any indexed word was used by Emily Dickinson. In the righthand columns of the table are the exceptions to the chronological sequence of poem numbers that Johnson discovered after the text of his edition went to press and noted in his introduction. (The date of number 1775 was established later.)

\begin{tabular}{|c|c|c|}
\hline \multicolumn{3}{|c|}{ Approximate } \\
\hline Poem number & date & Exceptions \\
\hline 1 & 1850 & \\
\hline 2 & 1851 & \\
\hline 3 & 1852 & \\
\hline 4 & 1853 & \\
\hline 5 & 1854 & \\
\hline $6-57$ & 1858 & \\
\hline $58-151$ & 1859 & \\
\hline $152-216$ & 1860 & \\
\hline $217-298$ & 1861 & $330-331,687$ \\
\hline $299-664^{*}$ & 1862 & 688,1072 \\
\hline $665-807^{*}$ & 1863 & \\
\hline 808-981 & 1864 & \\
\hline 982-1066 & 1865 & \\
\hline $1067-1103 *$ & 1866 & 1775 \\
\hline 1104-1113 & 1867 & \\
\hline $1114-1135$ & 1868 & \\
\hline 1136-1152 & 1869 & \\
\hline $1153-1176^{*}$ & 1870 & $1222,1770,1774$ \\
\hline 1177-1204 & 1871 & \\
\hline $1205-1242^{*}$ & 1872 & \\
\hline 1243-1292 & 1873 & \\
\hline 1293-1331 & 1874 & 1153 \\
\hline 1332-1351 & 1875 & \\
\hline $1352-1389 *$ & 1876 & 1575 \\
\hline
\end{tabular}




\begin{tabular}{lcl}
\multicolumn{3}{c}{ Approximate } \\
Poem number & date & Exceptions \\
$1390-1431$ & 1877 & \\
$1432-1452$ & 1878 & $1218,1237,1314$ \\
$1453-1482$ & 1879 & 1385 \\
$1483-1508$ & 1880 & \\
$1509-1536$ & 1881 & $1771-1772$ \\
$1537-1559$ & 1882 & 1760 \\
$1560-1593$ * & 1883 & 1768,1773 \\
$1594-1636$ & 1884 & \\
$1637-1646$ & 1885 & \\
$1647-1648$ & 1886 & \\
$1649-1775$ * & Undated \\
* See note, page xiii.
\end{tabular}

\section{Line Number}

The number of the text line, as given in the main texts of Johnson's edition, appears in the last column on the concordance page. A " $T$ " in this column instead of a number indicates that this line is one of the few titles supplied by Emily Dickinson. When a line number is preceded by a "V,"an alternative variant line is indicated; when a "V" is followed by no line number, an additional variant line is indicated. To explain more fully the origins of these variant lines, it is necessary to discuss the text on which this concordance is based and the methods needed to handle the variorum readings contained in that text.

\section{BASIC TEXT OF THE CONCORDANCE}

Unless the maker of a concordance attempts to re-edit a text in and through the concordance, his work will be only as good as the editions on which it is based. The chaotic early editions of Emily Dickinson's poetry provide a case in point. A partial concordance for these editions was done by Louise Kline Kelly as a doctoral dissertation at Pennsylvania State College in 1951. Confined to nouns, verbs, adjectives, and adverbs, Mrs. Kelly's "A Concordance of Emily Dickinson's Poems" gives the line-contexts of words occurring less than ten times in Emily Dickinson's poetry; words occurring more frequently are accompanied only by the page and line numbers of the editions where they may be found. Mrs. Kelly's dissertation was used by Johnson in preparing The Poems of Emily Dickinson. With its addition of forty-one new poems, its arrangement of the poems, and its inclusion of the numerous authorial variants for the poems, Johnson's edition rendered Mrs. Kelly's work obsolete. Yet as the acknowledgments in various works on Emily Dickinson testify, Mrs. Kelly's work has 
been a valuable aid to scholars and critics-and she has put the users of both Johnson's edition and this new concordance based on it considerably in her debt.

In his introduction to The Poems of Emily Dickinson Johnson wrote that the purpose of his edition was "to establish an accurate text of the poems and to give them as far as possible a chronology." Once a chronologybased on Mrs. Theodora Van Wagenen Ward's analysis of Emily Dickinson's changing handwriting-was established, the manuscripts were grouped together and the poems assigned numbers according to their place in the chronology. But before this could be done, Johnson had to select, from among the poems found in more than one manuscript, the texts that were to be given what he called "principal representation" in large type under the poem numbers. Holograph manuscripts survive for all but 119 of the 1,775 poems in the edition, and according to Johnson's classification these exist in one or more of three stages of composition: there are fair copies, which Emily Dickinson appears to have finished; there are semifinal drafts, which also appear to be finished except for alternative words or phrases written between the lines or at the sides or bottoms of the manuscripts; and finally there are work-sheet drafts, which range from rough jottings to elaborately reworked poems. Many of Emily Dickinson's poems are to be found in more than one manuscript state, and a number of them exist in two or more variant fair copies. In order to maintain the chronological order of the poems, Johnson chose, whenever possible, the earliest fair copy of each poem; other versions are given in smaller type below the main text. This decision has resulted in some misunderstanding and misuse of The Poems of Emily Dickinson because the text selected for principal representation is not always the best version of the poem. A later fair copy of an earlier semifinal draft may contain readings that are better poetry than those in the earliest fair copy; or the alternative words written at the bottom of a semifinal draft may be preferable to those in the body of the poem. Subsequent editors using Johnson's edition have too often selected a text of inferior poetry just because it was given principal representation in this edition. In order to base a concordance on The Poems of Emily Dickinson it was necessary to follow the main texts given by Johnson; yet it was also essential to present the numerous and important variants to the carliest fair copies or, in the absence of these, to whatevcr text was given principal representation under a poem number. A concordance to Johnson's variorum edition had, in other words, to be a variorum concordancc. Before considering how these variants were included in the concordance, however, it is important to note certain modifications in Johnson's text that have been adopted in the concordance. 


\section{Changes in Wording Adopted for the Concordance}

The basic text for this concordance is the 1958 second printing of the three-volume variorum The Poems of Emily Dickinson, published by Harvard University Press. (This edition should not be confused with the one-volume The Complete Poems of Emily Dickinson, also edited by Johnson and published in 1960, which is not a variorum text.) The second printing of The Poems of Emily Dickinson differs from the first mainly in its inclusion, on the verso of the title page to the edition's appendix, of a list entitled "Corrections." The substantive changes in the poetry of the edition to be found in this list and in the text of the concordance are the corrections of "teases" to "teazes" (poem 319, 1. 6), "has" to "had" (1254, l. 1 of the work-sheet draft), "revelry" to "revery" (1526, l. 12 of the Todd transcript), and "the" to "a" (87, 1. 2). Two dashes were added at the ends of lines (290, 1. 4, and 299, 1. 4 of the copy sent to Susan Dickinson). Also corrected in the text of the concordance were the errors noted by Charles R. Anderson in his Emily Dickinson's Poetry (New York, 1960), pages $312,321,324-325$; these include the change of "the" to "this" (1068, 1. 11 of the copy sent to Niles), the addition of a dash at the end of a line $(1271,1.7)$, and the addition of "swift" to the list of variants for the phrase "sudden legacy" (1333, 1. 5 of the work-sheet draft). Corrections of obvious misprints that I have found while preparing Johnson's text for the concordance involved changing "unknow" to "unknown" (78, 1. 8 of the penciled copy), "Feet" to "Fete" (794, variant note to 1.16 ), "world" to "would" (1133, variant note to l. 8), "he" to "her" (1496, variant note to 1.11 ), and "departure" to "departing" (1773, variant note to 1 . 3 ). Also corrected were the minor mistakes in the line- number listings of variants to poems $532,577,1479,1508$, and 1646. I have also added two titles to the twenty-six titles of Emily Dickinson's poems noted by Johnson in Appendix 8 of his edition: "Valentine Week," which Johnson gives as the first line to poem 1, and "Diagnosis of the Bible, by a Boy-" the title of a semifinal draft of poem 1545.

\section{Changes in Spelling and Punctuation Adopted for the Concordance}

The limitations of our IBM printing equipment necessitated five kinds of changes in the punctuation, spelling, and capitalization of The Poems of Emily Dickinson. Although the special print wheels made for the Cornell Concordances enabled this concordance to employ all the punctuation marks that Emily Dickinson used, it was not possible to reproduce lower-case letters. The brackets that Johnson occasionally used to indicate his insertion of a letter or his reconstruction of a torn manuscript were silently dropped because brackets were needed to include variants in the 
concordance. (The following poem and line numbers indicate all the places where brackets were used in Johnson's edition: number $43,1.4 ; 58$, l. $7 ; 233$, 1. 4; 264, 1. 4; 371, l. 11; 373, 1. 4; 419, 1. 13; 588, 1. 21; 608, 1. 5; $976,1.4 ; 1133,1.2$; and $1685,1.6$.) Twice in her poetry $(62,1.9$, and 142 , 1. 11) Emily Dickinson used numbers in her text; these were spelled out in the concordance because her punctuation had to be coded by numbers to prepare it for the computer. The single quotation marks to be found in four of Emily Dickinson's poems (82, 1. 4; 103, 11. 11, 16; 127, 11. 1, 2, 5; and $175,1.1$ )-none of which followed double quotation marks-had to be changed to the double quotation marks usually found in her poetry because the computer's processes of alphabetization treated single quotation marks as if they were apostrophes. Finally, it was impractical to program a computer and a printer to print lines under or through words. As a result, the cancels and underlinings in Emily Dickinson's manuscripts are not reproduced in the concordance. Because less than 1 per cent of the more than 100,000 words in her manuscripts are canceled, this limitation is not very significant. There are even fewer instances of underliningsalmost all of them occur with variants in semifinal drafts-yet these have greater importance, because Emily Dickinson appears to have indicated to herself the alternative choices she preferred by underlining them. Nevertheless, Johnson notes instances where later fair copies of poems do not adopt the underlined variants of earlier drafts, and he concludes that "the mood of the moment played its part." One of the small sacrifices involved in applying a computer, with its peripheral equipment, to Emily Dickinson's poetry is the machine's inability to convey the results of these moods.

\section{Changes in Emily Dickinson's Canon Not Adopted in the Con- cordance}

In his review of Johnson's edition in the New England Quarterly (XXIX [1956], 242-243), Jay Leyda noted that the number of poems in Emily Dickinson's canon was less than the 1,775 given by Johnson because in three instances (331 and 342, 937 and 992, 1525 and 1616), poems numbered separately are actually variant versions of other poems in the canon. And after writing his review Leyda discovered that the last poem in The Poems of Emily Dickinson is actually a stanza from a lost variant version of poem 1068, which he located and which is given in Anderson's Emily Dickinson's Poetry (pp. 324-325); this version also includes one new variant ("candles" for "candle" in 1.18 of the Norcross transcript of poem 1068), which was adopted in the concordance. Except for the addition of this variant, these important modifications of Emily Dickinson's 
canon have not been adopted in the text of the concordance, however, because of the confusions that would result if all the poem numbers after number 331 were changed. In several instances, then, identical lines with different poem numbers will appear together in the concordance; the reader should not forget that these lines belong to versions or parts of the same poem.

\section{VARIANTS}

Only seven of Emily Dickinson's poems were published in her lifetime, none of them with her clear consent. Many of her poems are "unfinished" in the sense that she never made final choices among the variants in drafts and copies. If she "found the words to every thought" but one, she often failed to indicate finally what the words were; even in this line she wrote a variant, and the line appears in the concordance as I FOUND THE woRDS [PHRASE] to EVERy thought. The principal problem in editing Emily Dickinson's poetry for the concordance was how to present in individual lines of poetry the variants that in Johnson's edition are given either in separate versions or as notes at the end of the poems. One solution would have been to expand all variants into variant lines, but, in addition to increasing the automatic word-frequency counts given in the appendix to the concordance, such a method would not show a crucial feature of the variant's context-the word or words for which the variants were introduced. A single method of handling all the variants was abandoned, therefore, and the kinds of variants were treated in different ways, according to whether they were words, phrases, lines, or complete versions of poems.

\section{Variant Phrases}

Although variant words could be enclosed within brackets and inserted into the lines after the words for which they were variants, variant phrases could not be handled in quite the same way. Frequently the phrases could not be matched, word for word, with the phrases in the main text, and breaking up the variant phrases would have ignored the unity-hence often the meaning-of the phrases. Sometimes it was impossible to do otherwise, but in many instances the words of a variant phrase could be kept together and inserted within brackets after the phrase in the main text; and as with variant words, it is usually possible for the reader to see how far back in the line the variant phrase refers by counting the syllables of the variant and of the words preceding it. When the variants differ in the number of syllables from the preceding phrases, the sense of the inserted phrase usually makes clear what words the variants replace; when 
it does not, the user of the concordance must have recourse to Johnson's edition.

Sometimes the editing of variants into the lines of the principal texts involved adding words from the texts to the phrases. In poem 1343, for instance, Emily Dickinson wrote as variants for the phrase "Was all that saved" first "alone sustained-" and simply "upheld-" after that. To make the position of the variants clearer, Johnson uses a bracketed "Alone" with "upheld." Here as elsewhere Johnson's clarification of variants was followed, and the line appears in the concordance as follows:

\section{WAS ALL THAT SAVED [ALONE SUSTAINED-/ALONE UPHELD-] A BEE}

In addition to the interpolations given by Johnson other words from the text were occasionally used to clarify the location of a variant. It should be stressed, however, that the editing procedure for variant phrases does not involve adding or removing words from Emily Dickinson's poetry, but simply filling out elliptical phrases with words from the main text or removing repetitions that the poet used to indicate the place of a variant phrase in a line. Even with these procedures it was not always possible to avoid repetition, as the example above shows. Nor was it always possible to keep the different words of a variant phrase together. Where keeping the words of a variant phrase together would have meant repeating nearly an entire line, it seemed better to separate the words than to swell the bulk of the concordance and the word frequencies. Sometimes the various combinations requiring insertion were too complex to be fitted together as one or more variant phrases; in these instances the phrases were treated word by word or were combined into separate variant lines. The texts involved in this kind of editing were almost always work-sheet drafts, the definitive reconstruction of which is impossible.

\section{Variant Lines}

Lines both numbered and marked with a "V" are those clearly variant to a particular line in the main text of Johnson's edition; the number of the variant line is the same as that of the line for which it is a variant. Unnumbered variant lines are taken from lines and stanzas of drafts that were not included in the versions given principal representation in The Poems of Emily Dickinson. Also treated as variant lines are phrases that lack only a word or two of being completely different variant lines; the missing words are supplied from the original lines. Complicated series of variants that could not be bracketed into lines of the main texts are also handled as variant lines. In the most involved cases-again work-sheet drafts in which Emily Dickinson's final decision cannot be definitively re- 
constructed-variant words and phrases are bracketed into lines that are themselves additional, unnumbered variant lines.

\section{Variant Poems}

For ten poems in Johnson's edition (148, 216, 433, 494, 824, 1213, 1282, 1357, 1358, and 1627) the texts given principal representation consist of two versions of one poem. Because these double versions constitute, in effect, two poems under one number, and because it was not possible in the format of the concordance to identify poems beyond their numbers and shortened first lines, it was necessary to combine each double version. Where there are only minor differences between versions (as in numbers 494,1213 , and 1282), certain words of one version are included as variants to the other. For double versions that contain more substantial variants, numbered and unnumbered variant lines are used. How these were employed can be illustrated by the best-known double-version poem, "Safe in their Alabaster Chambers-" (number 216). The earliest fair copy of the poem is the 1859 version, which was taken as the main text in the concordance; the lines of both the 1861 fair copy and its work-sheet draft are treated as variants to the 1859 version. The additional lines and stanzas of the 1861 manuscripts are not clearly variant to specific lines of the 1859 manuscript; hence they had to be listed as unnumbered, additional variant lines. And just as the arrangement in Johnson's edition does not imply any evaluation of the quality or authority of the two versions, so in the concordance the unnumbered variant lines are no less significant or valuable than the numbered ones.

\section{Punctuation of Variants}

When the punctuation with variant words differs from that of the main text in Johnson's edition, the difference usually consists in the addition of a dash following the variant. These differences are not reproduced in the concordance, because Emily Dickinson seems to have used the dash with variants mainly to separate alternative choices. The punctuation of variant phrases is followed exactly, however. When the final punctuation of a variant phrase is identical with that in the principal text, it is given after the bracketed variant phrase, indicating that the punctuation is the same for both the main-text reading and the variant. When the terminal punctuation of variant phrases differs from that in the main text, the variant punctuation follows the variant phrase within the brackets, and the final punctuation of the main-text phrase precedes the bracketed variants. 


\section{Omitted Variants}

The Poems of Emily Dickinson includes certain types of variants that are irrelevant to the uses of the concordance. Variants in syntax alone, unaccompanied by variants in wording, were omitted from the concordance, as were changes in spelling and punctuation; variants in spelling that suggested different words ("straight" and "strait," for example) were retained in the concordance, however. Variants in line or stanza order were not included because there was no way of presenting them in the single lines of the concordance. Variants in published versions of poems were also excluded when versions of these poems were extant in manuscripts or authoritative transcripts; Johnson's inclusion of all published variants makes a fascinating record of editorial corruption, but there is no point in perpetuating these corruptions in a concordance. Three exceptions were made to this policy: the variants in published versions of poems 59 and 160 were included because they appear to derive from manuscripts now lost, and the published second stanza of poem 57 was retained because it poetically complements the stanza of a poem to be found in a manuscript, part of which has been torn off. Poems in Emily Dickinson's canon that have survived only in their published forms were, of course, included in the concordance.

Finally, it was not possible within the format of a computer concordance to indicate the numerous sources of the variants that had to be edited into the lines of the earliest finished text or included as numbered and unnumbered variant lines in preparing the text of Emily Dickinson's poems for the computer. Yet because it does not indicate whether variants derive from fair copies, semifinal drafts, work sheets, or transcripts, the concordance should not be taken as making new composite poems out of differing versions that a private poet left unfinished. By simply ignoring the bracketed insertions and the lines marked with " $V$ " the user can determine all the poems chosen by Johnson as the principal texts of his edition. If the reader wants to find the source of a given variant in the concordance, he must return to the variorum edition. And it is worth stressing again that the concordance can be most effectively used in conjunction with The Poems of Emily Dickinson.

\section{ACKNOWLEDGMENTS}

Without the help of a number of individuals and institutions this concordance could not have been made. Professor S. M. Parrish, the general editor of the Cornell Concordances, anticipated and solved many of the 
problems that beset the making of a computer concordance, and the finished work owes much to his energy and enthusiasm. To the interest and ingenuity of James A. Painter, the computer programmer, are due special features of the concordance that might not have been possible without his help. The sine qua non of this concordance is, of course, Thomas H. Johnson's superb The Poems of Emily Dickinson, which was used by the kind permission of the Harvard University Press and the Trustees of Amherst College.

A grant from the Grant-in-Aid Fund of the Department of English, Cornell University, covered the clerical costs of preparing Emily Dickinson's poetry for the computer, and a research grant from the Graduate School of Indiana University made it possible for me to spend a summer preparing the text of the poems. The Cornell Aeronautical Laboratory, Buffalo, New York, generously made its computer and other facilities available. The Indiana University Computing Center gave free use of its peripheral equipment; I am grateful to Dale J. Hall, the executive director of the center, for helpful advice about the equipment's possibilities. The computer centers at Cornell and Brown universities also made their facilities available at crucial stages in the preparation of the concordance. Marta Petoe and James Free punched and verified the text of the poems with impressive accuracy and speed, and Sophia Boyatzes Blaydes helped greatly with the proofreading of the punched text.

To Professors M. H. Abrams, Ephim G. Fogel, William R. Keast, and especially the late Stephen E. Whicher-members of the Cornell Concordance Supervisory Committee-I am grateful for much helpful advice and criticism. My wife's multifarious aid and cheerful endurance are beyond gratitude.

S. P. Rosenbaum

Barrington, Rhode Island

April 1964 
A Concordance to the Poems of EMILY DICKINSON 
